Article

\title{
Sentinel-1 for Monitoring Reservoirs: A Performance Analysis
}

\author{
Donato Amitrano 1, Gerardo Di Martino 1, Antonio Iodice 1, Francesco Mitidieri ${ }^{2}$, \\ Maria Nicolina Papa ${ }^{2}$, Daniele Riccio ${ }^{1}$ and Giuseppe Ruello ${ }^{1, *}$
}

1 Department of Electrical Engineering and Information Technology, University of Napoli Federico II, Via Claudio 21, 80125 Napoli, Italy; E-Mails: donato.amitrano@unina.it (D.A.); gerardo.dimartino@unina.it (G.D.M.); iodice@unina.it (A.I.); daniele.riccio@unina.it (D.R.)

2 Department of Civil Engineering, University of Salerno, Via Giovanni Paolo II 132, 84084 Fisciano (SA), Italy; E-Mails: francescomitidieri88@gmail.com (F.M.); mnpapa@unisa.it (M.N.P.)

* Author to whom correspondence should be addressed; E-Mail: ruello@unina.it; Tel.: +39-081-7683512; Fax: +39-081-7683149.

External Editors: Salvatore Stramondo and Prasad S. Thenkabail

Received: 16 May 2014; in revised form: 23 October 2014 / Accepted: 24 October 2014 / Published: 4 November 2014

\begin{abstract}
In this paper we explore the performances and the opportunities provided by the European satellite Sentinel-1 for water resource management applications in low-income countries. The analysis is supported by a synthetic aperture radar (SAR) simulator, which allowed the quantification of the expected characteristics of Sentinel-1 products in three applications: interferometric digital elevation models (DEMs) generation, land cover mapping and estimation of water volumes retained by small reservoirs. The obtained results quantitatively show that Sentinel-1 data characteristics are fully suitable for most of the application already explored in the recent SAR literature.
\end{abstract}

Keywords: Synthetic Aperture Radar; Sentinel-1; water resources; semi-arid regions; reservoirs management

\section{Introduction}

The United Nations estimated that, by $2025,1.8$ billion people will live in regions characterized by water scarcity and two-thirds of the world's population will be faced with a lack of water [1]. According to recent studies about the growth of global population (up to 8.3 billion in 2030 [2]), in ten years, water 
scarcity could affect almost 5.5 billion people. This scenario is also exacerbated by desertification (principally caused by unsustainable land management practices) which increases the pressure on water resources worldwide [3]. In fact, desertification, land degradation and drought globally affect 1.5 billion people, 24\% of which are in Sub-Saharan Africa [4].

Today, about $66 \%$ of Africa is arid or semi-arid and more than one-third of the Sub-Saharan population lives in a water-scarce environment with less than $1000 \mathrm{~m}^{3}$ available per capita [5]. In these areas, rural population mainly relies on small reservoirs for water harvesting in the rainy season [6]. As an example, in Burkina Faso, it is estimated that 1700 reservoirs are actually employed for agricultural activities, livestock watering and human consumption [7]. They are used to cultivate in counter-season, incrementing the food production and, therefore, the resilience to famine.

Despite their crucial importance, many small reservoirs are neither monitored nor surveyed, due to high costs required by the setup and management of a sensor network. Hence, a complete and up-to-date catalog of location and maximum capacity of the reservoirs is not available, even because they are often built by an initiative of farmers' associations, without general planning.

In this context, remote sensing could be a powerful instrument, allowing a strong reduction of costs and time necessary to obtain relevant information for an effective management of water resources. Thus far, remote-sensing projects have mainly embraced the use of optical data (even thanks to the availability of free LANDSAT imagery), accepting the risk of acquisitions affected by cloud cover, a frequent event in the rainy season.

The use of Synthetic Aperture Radar (SAR) data was rather limited in past applications because of the high costs of data and the complexity of their interpretation by non-expert users. Moreover, the recent SAR literature about water resources monitoring in semi-arid regions is mainly related to sensors (ENVISAT, ERS and more) with low resolution (almost $20 \mathrm{~m}$ ) imaging capability [8-10].

The most relevant project from the last few years in terms of water resources monitoring is the TIGER initiative, promoted by the European Space Agency (ESA) [11], which aims at assisting African countries to collect, analyze and disseminate water-related geo-information through the exploitation of remotely sensed data. Under the aegis of TIGER, several activities and projects regarding water-related issues have been supported. TIGER thus represented a framework within which European institutions and local African partners shared experiences and expertise stimulating the dissemination and the enforcement of respective knowledge. This led to the achievement of remarkable results as, for example, in the fields of trans-boundary groundwater management [12], land cover mapping [13], water bodies detection [14] and small reservoirs bathymetry [8].

Valuable results have been obtained relating basins' surface areas with retained water volume for northeastern Ghana [9]. These relations are extremely useful since they allow for the extraction of the available water volume through the estimation of a reservoir's surface. This activity can be successfully carried out with remotely sensed data, thereby avoiding expensive bathymetric surveys.

These expressions can be extended to other morphologically similar areas, where bathymetric surveys and/or a suitable DEM are not available. In particular, the almost uniform morphology of the Sahelian region gives the opportunity to use few calibration gauges. This possibility was also supported by the results of the comparison between area-volume relationships extracted from two datasets belonging to different areas of the Sahelian region [15]. 
The introduction of the new generation of high-resolution sensors (such as COSMO-SkyMed, TerraSAR-X and Sentinel-1) allows for an effective monitoring of small reservoirs. In fact, as discussed in [15], COSMO-SkyMed imagery has been successfully employed for the study of basins with extension of few thousand square meters. The data on water retention at reservoirs can be used also for the implementation and calibration of hydrological models, as suggested in [16]. One of the main limits of COSMO-SkyMed imagery is the significant cost required for acquiring a complete dataset.

The recent launch of Sentinel-1, the new ESA SAR sensor, solves the problems related to the cost of images, since ESA proposes a free data distribution policy. The interpretation of the SAR images is still a limit for the diffusion of this technology, because the image characteristics depend on the geometrical and electromagnetic properties of the observed surfaces. The comprehension of the geometric distortions introduced by the side-looking acquisition mode [17] and of the non-linear electromagnetic scattering phenomena that contribute to the SAR signal formation requires the quantitative knowledge of the interactions between the transmitted electromagnetic field and the physical surfaces of the imaged scene. Therefore, several works in the past literature expressed the necessity of remote sensing processing chains devoted to produce results that could be easily interpreted by the potential end-users [18-20].

In this paper, we present an analysis of the potentiality of Sentinel-1 in water resource monitoring activities. The analysis is supported by a SAR raw signal simulator and is focused on applications concerning water-related problems in semi-arid regions.

The work is organized as follows. In Section 2, we recall the main characteristics and results of the Water Resources Management in Semi-Arid Regions (WARM-SAR) project, which produced significant results for water resource management from high-resolution SAR data. Sections 3-5 deal with an analysis of the new opportunities offered by Sentinel-1: in Section 3, the main characteristics of the mission are recalled; Section 4 is devoted to introducing the SAR simulator used for the quantitative analysis of the Sentinel-1 performances; and, in Section 5, we present the results obtained by processing the simulated Sentinel-1 images. We provide specific results aimed at the production of DEM and related products, land cover maps and monitoring of water volumes. Implications of the use of this new sensor in the hydrological modeling of the study area are discussed throughout the examples. Conclusions are drawn at the end of the work.

\section{Water Resources Monitoring in Semi-Arid Regions: The WARM-SAR Project}

In this section, we recall the results of the WARM-SAR project, which is devoted to exploring the possible uses of SAR images for water resource monitoring.

WARM-SAR exploited a set of 16 stripmap ( $3 \mathrm{~m}$ resolution) and 7 spotlight $(1 \mathrm{~m}$ resolution) images with coverage of almost one year and a half, provided at no cost by the Italian Space Agency (ASI) under the aegis of the 2007 COSMO-SkyMed Announcement of Opportunities [21]. The SAR images cover a rectangular area of almost $1600 \mathrm{~km}^{2}$ of the Yatenga district in the north of Burkina Faso, a small West African country where nearly $80 \%$ of the 14 million inhabitants live in rural areas and the main economic activity consists of subsistence farming and ranching. More than two million people are food insecure and about $34 \%$ of the population is subject to chronic malnutrition [22]. The region is characterized by a semi-arid climate, with a rainy season lasting three months. 
In the frame of the WARM-SAR project, we developed specific applications for low-income countries characterized by a semi-arid climate. In order to estimate the performance expected by the use of Sentinel-1 data in a similar context, in this section we recall the basic principles of the following applications:

1. Digital Elevation Models (DEMs) generation and related products;

2. Land cover mapping;

3. Monitoring of water volumes retained at reservoirs.

\subsection{Digital Elevation Models (DEM) Estimation and Related Products}

In [23], a reliable DEM was extracted by means of an interferometric processing of two images acquired at the end of the dry season, when the interferometric coherence is expected to be sufficiently high. The resolution of the DEM ( $9 \mathrm{~m}$, obtained by the 3 -multilook of the $3 \mathrm{~m}$ input SAR data) is significantly higher with respect to those previously available: SRTM (resolution $90 \mathrm{~m}$ ) and ASTER (resolution $30 \mathrm{~m}$ ). The availability of such a high-resolution DEM allows the estimation of the bathymetry of the small reservoirs that dry up completely at the end of the arid season [15] and the derivation of an analytical relation between reservoirs' surface area and retained volume.

The estimate of the reservoirs bathymetry from remotely sensed imagery provides valuable information about reservoir capacity. In fact, in Sahel, where sedimentation of the reservoirs due to strong soil erosion is extremely fast [24] and quickly changes the topography, there is a lack of updated topographic information. The average sedimentation rates for six reservoirs of the study area were estimated, concluding that, in about 20-30 years, most of the studied reservoirs lost more than $70 \%$ of their original capacity [25].

\subsection{Land Cover Map Production}

The availability of repeated acquisitions offered by new-generation sensors opens new perspectives for remote-sensing applications in semi-arid environments through the definition of new products which fully exploit the particular Sahelian climate [23]. In fact, as discussed in [19], the occurrence of a condition of aridity of the scene at the peak of the dry season makes it possible to establish a reference scenario for the other available images. The procedure for building the Level-1 $\alpha$ products is presented in [19] and an example relevant to a small reservoir of the Yatenga district is depicted in Figure 1. The reference image, loaded on the blue band, was acquired at the end of April, i.e., at the peak of the dry season. The test images and the interferometric coherence are assigned to the green and red band, respectively.

This combination of bands makes easy the users' pre-attentive processing, i.e., the unconscious accumulation of information from the environment [26], since it allows for an association between relevant physical features of the scene and the colors restituted by the RGB map, which is consistent with human expectation. With reference to Figure 1, this happens, as an example, for seasonal water, and for seasonal vegetation, which are displayed in blue and green, respectively.

As for the seasonal water, the blue color results from the prevalence of the backscattering from rough soil emerging in the dry season image (blue band) when there is no water in the intake, with respect to the backscattering from flat water surface occurring in wet season images (green band). 
As for the seasonal vegetation, the green color results from the prevalence of the backscattering from the vegetation emerging in the wet season images (green band) with respect to the backscattering from rough surfaces occurring in the dry season image (blue band), in absence of vegetation [27].

In both the cases, the coherence (red band) is almost null.

When the electromagnetic response of the reference image and of the test image is comparable, the map exhibits a cyan tonality. Where both the reference and test image are covered by surface water, due to the weak electromagnetic response in these two bands, the composition restitutes the black color (see the dark area in the immediate proximity of the dam in Figure 1).

Figure 1. Level-1 $\alpha$ product detail of a small basin near to the Aoérama settlement (test image 31 August 2010).
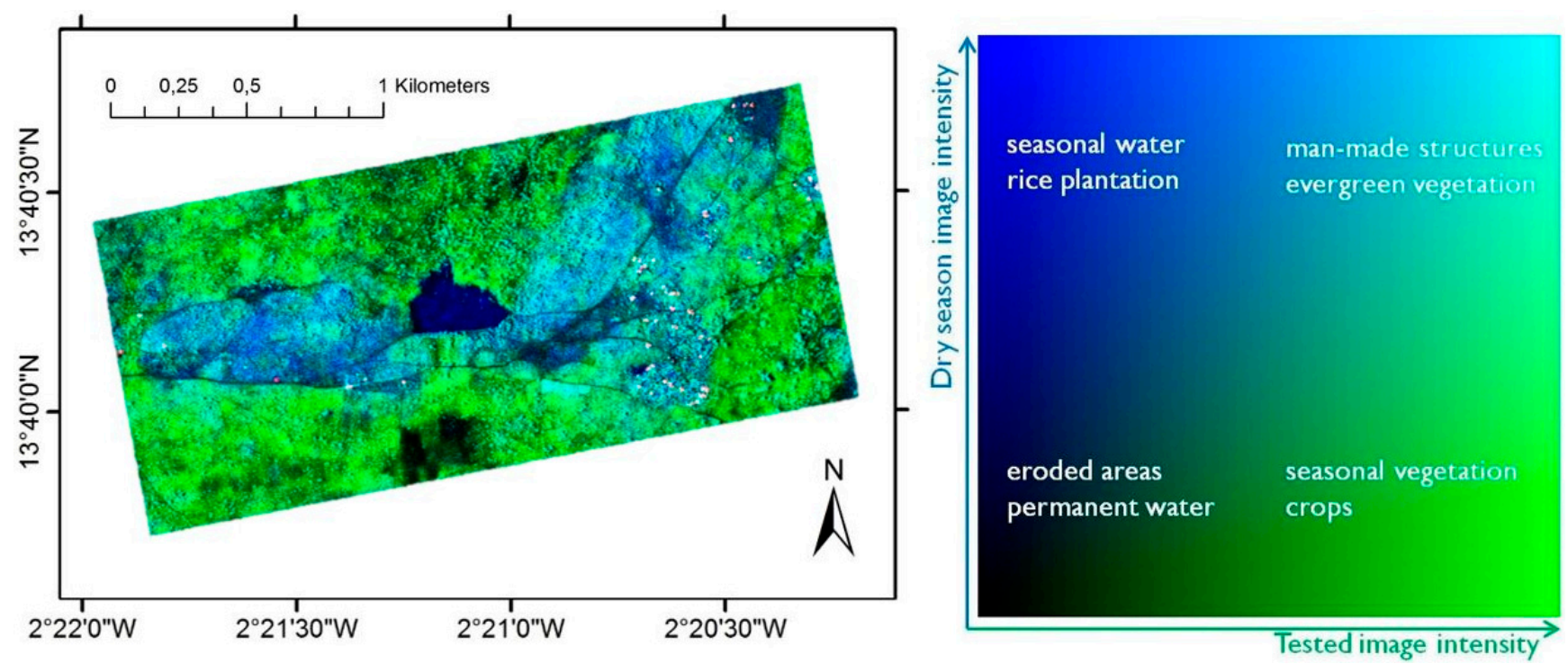

The main characteristics of the Level- $1 \alpha$ products are the congruence with human vision, which allows for an immediate understanding of the more relevant natural cycles of a semi-arid environment (i.e., those of water and of vegetation), and the class detachability. The latter, in particular, makes these products very attractive for supervised classification procedures, even using extremely simple algorithms.

The aforementioned characteristics of Level-1 $\alpha$ imagery provide a tool for a quick estimation of the reservoirs' surface areas for several basins, from which it is possible to retrieve the retained water volume, as is explained in Section 5. Thus, these products can be managed by a large variety of scientists and researchers, even non-experts in SAR issues, and could, therefore, potentially increase the use of such data, thereby bringing benefits to water-related research activities.

\subsection{Monitoring of Water Volumes Retained at Reservoirs}

The areas covered by water were extracted by the intensity SAR images despeckled using an optimal weighting multitemporal De Grandi filter [28]. This technique allows amplifying the water-land contrast and producing more accurate information on the extension of water surfaces. A further speckle reduction was obtained by a spatial multilooking, which reduced the images' resolution to $9 \mathrm{~m}$, in accordance with DEM resolution. 
The coupled measures of water surface and DEM led to the estimation of water volumes retained by the dam. The retrieved data were used to validate a simple hydrological model [15]. The time evolution of the water storage was computed by the implementation of a balance between the incoming and outgoing water flows.

In order to validate the model, the computed storages are compared with those extracted from SAR data. In spite of the assumptions made and of the uncertainties linked to the estimation of some of the input data, the model was able to catch the overall behavior of the system and, therefore, can be used for the simulation of different scenarios of water abstraction from the reservoirs and, therefore, to optimize the resource management. Another important application of the proposed model is the estimation of the impact of small reservoirs on the downstream flow, which a crucial information in case of water conflicts [8].

\section{Sentinel-1: The Mission}

Despite the great potentiality offered by WARM-SAR and similar projects, the scaling and the capillary diffusion of the derived products is still constrained by technical and economical limits, especially in low-income countries, where most of the potential beneficiaries of the proposed products can not sustain the cost of commercial data.

The aim of the Sentinel mission is to support the Copernicus program, offering a significant scientific opportunity thanks to: (i) a broad variety of sensing methods, (ii) the compatibility with past ESA mission (in the case of SAR this holds for ERS and ENVISAT) [29], and (iii) the distribution policy, which will guarantee free, full and open access to data. Therefore, the capacity of acquiring, interpreting and processing Sentinels' data will be crucial for the success of projects involving geographical information.

Sentinel-1 is a two-SAR satellite constellation designed to guarantee global coverage with a revisit time of 6 days. The first satellite (Santinel-1A) was launched on 3 April 2014. A 12-meter long radar working in C-band was successfully deployed and is starting to acquire images all over the world. Sentinel-1A is placed in a near-polar, sun-synchronous orbit with a 12-day repeat cycle and 175 orbits per cycle. Both the satellites of the Sentinel-1 constellation share the same orbit plane with a $180^{\circ}$ orbital phasing difference.

Sentinel-1 is designed to work with four different possible operative modes: (i) stripmap, (ii) wave, (iii) interferometric wide swath and (iv) extra wide swath. It supports dual polarization acquisition $(\mathrm{HH}+\mathrm{HV}$ or $\mathrm{VV}+\mathrm{VH})$ for all the modes, with the exception of the wave mode (see Table 1). The medium resolution of the stripmap is very close to the resolution of the images used for the development of the products introduced in Section 2. In the following sections, also with the use of a SAR raw signal simulation, we present a study of the expected performances of Sentinel-1 in the design and development of the products presented in the frame of the WARM-SAR project.

Table 1. Sentinel-1 operative modes.

\begin{tabular}{cccc}
\hline Mode & Swath $(\mathbf{k m})$ & Resolution $\mathbf{( m \times \mathbf { m } )}$ & Polarization \\
\hline Stripmap & 80 & $5 \times 5$ & Dual \\
Wave & 20 & $5 \times 5$ & Dual \\
Interferometric WS & 250 & $5 \times 20$ & Dual \\
Extra WS & 400 & $20 \times 40$ & Single \\
\hline
\end{tabular}




\section{Sentinel-1: SAR simulation}

In this section, we introduce the basic concepts of SAR raw signal simulation, which is here used to simulate both Sentinel-1 and COSMO-SkyMed data and to discuss the expected performances of Sentinel-1 in the development of the WARM-SAR applications described in Section 2.

Let $x$ and $r$ be the independent space variables, standing respectively for azimuth and range. By using primed coordinates for the independent variables of the SAR raw signal, $s\left(x^{\prime}, r^{\prime}\right)$, this can be expressed as [30]:

$$
s\left(x^{\prime}, r^{\prime}\right)=\iint \gamma(x, r) g\left(x^{\prime}-x, r^{\prime}-r ; r\right) d x d r,
$$

where $\gamma(x, r)$ is the reflectivity pattern of the scene, and $g\left(x^{\prime}-x, r^{\prime}-r ; r\right)$ the unit impulse response of the SAR system [30]. Therefore, in order to obtain $s\left(x^{\prime}, r^{\prime}\right)$ we need to evaluate both the reflectivity function and the impulse response of the system.

The evaluation of the reflectivity function requires the use of adequate electromagnetic scattering models, able to provide the solution of interest as a function of the considered sensor and surface parameters. Hence, we need a description of the macroscopic aspects of the surface at the scale of the sensor resolution: this is accomplished by providing as input to the simulator a DEM. The behavior of the DEM is then approximated using a two-scale model [30], i.e., using plane facets, over which a microscopic random roughness is superimposed. Then, the mean square value of the field backscattered from each facet can be evaluated providing an adequate stochastic description of the microscopic roughness. The roughness can be described using parameters resulting from the introduction of different models for the shape of the surface [31]: in the present paper, the roughness is described through a fractal fractional Brownian motion (fBm) process [31], i.e., using only two independent parameters, the Hurst coefficient $H$ and the topothesy $T$ [m]. Finally, to complete the description of the surface, the relative dielectric constant $\varepsilon$ and the conductivity $\sigma[\mathrm{S} / \mathrm{m}]$ of the observed surface must be provided as input to the simulator. The small perturbation model, with the appropriate fractal power law spectrum, can be then used for the evaluation of the reflectivity function of the surface [31].

Note that the reflectivity function is evaluated in a ground range-azimuth reference system and is necessary to project it in the sensor-centered slant range-azimuth reference system. After this transformation, the obtained reflectivity function is filtered according to the impulse response of the SAR system, providing as output the raw signal, as shown in Equation (1). In order to compute the impulse response, the radar and orbital parameters of the sensor are needed: satellite height $h$ and velocity $v$, the sensor look angle $\theta$ and frequency $f_{0}$, the chirp duration $\tau$ and bandwidth $B$, the sampling rate $f_{s}$, and the pulse repetition frequency PRF. Finally, after standard focusing, the obtained raw signal provides the final simulated complex SAR image. The block diagram of the algorithm employed to evaluate the raw signal is depicted in Figure 2.

Another important aspect of the simulation procedure is the appropriate inclusion of the speckle effect [32]. Its presence is accounted for thanks to the aforementioned two-scale model. In fact, thanks to this approach, the spatial scales both smaller and larger than the resolution can be treated differently. In particular, the signal macroscopic behavior is described evaluating the mean square value of the field scattered from the plane facets locally approximating the considered surface, assuming knowledge of the microscopic roughness parameters $(H$ and $T)$ and the electromagnetic parameters $(\varepsilon$ and $\sigma)$ of the 
surface [31]. Conversely, the microscopic behavior, which determines the presence of speckle, is introduced via a statistical model: in this paper, we assume a fully developed speckle [32,33], and the amplitude-signal value obtained for each facet is multiplied by one specific realization of a Rayleigh random variable [30].

Figure 2. Block diagram of the SAR raw signal simulation. Radar (RD) and orbital (OD) data, along with the geometric $(z)$ and electromagnetic $(\varepsilon$ and $\sigma)$ parameters of the surface are the required inputs.

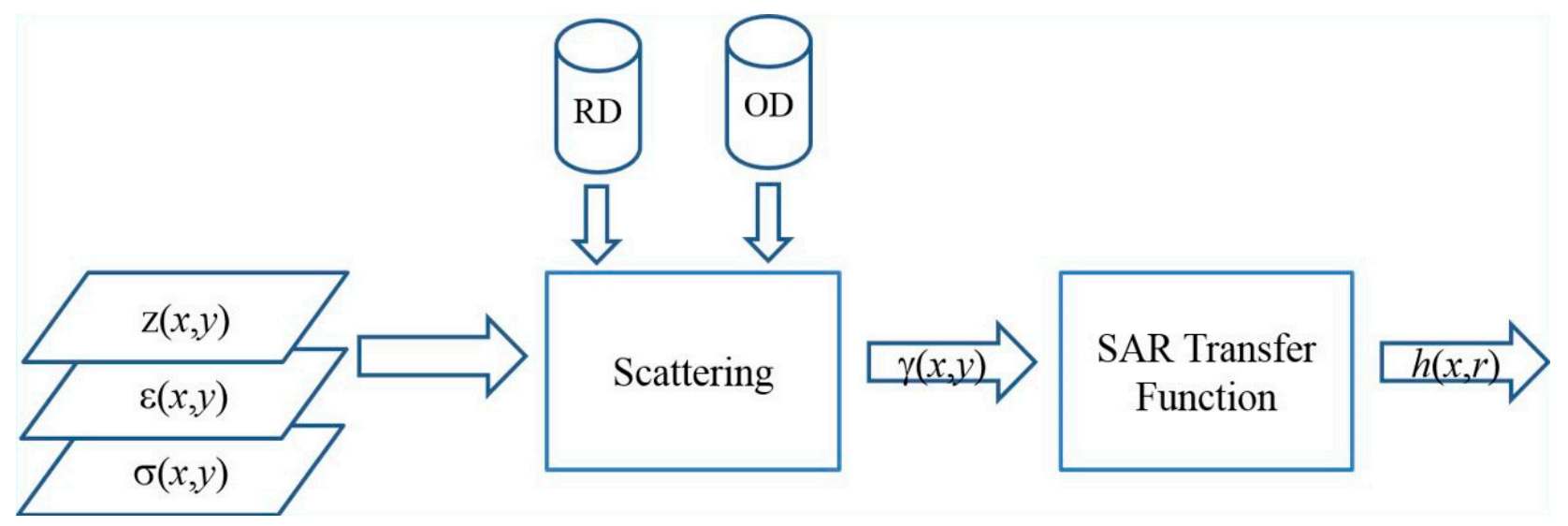

In Table 2, the parameters used for the simulation of Sentinel-1 and COSMO-SkyMed images are reported. With these parameters, we obtain a pixel spacing in azimuth-ground range on the final images of $4.66 \mathrm{~m} \times 5 \mathrm{~m}$ for Sentinel-1 and $2.08 \mathrm{~m} \times 2.33 \mathrm{~m}$ for COSMO-SkyMed.

Table 2. Simulation parameters.

\begin{tabular}{ccc}
\hline Simulation Parameter & Sentinel-1 & COSMO-SkyMed \\
\hline$h[\mathrm{~km}]$ & 693 & 619.6 \\
$v[\mathrm{~m} / \mathrm{s}]$ & 7 & 7.5 \\
$\theta\left[{ }^{\circ}\right]$ & 30 & 33.6 \\
$f_{0}[\mathrm{GHz}]$ & 5.405 & 9.3 \\
$\tau[\mu \mathrm{s}]$ & 35 & 35 \\
$B[\mathrm{MHz}]$ & 60 & 65.64 \\
$f_{s}[\mathrm{MHz}]$ & 60 & 116.25 \\
$\mathrm{PRF}[\mathrm{Hz}]$ & 1500 & 3612.7 \\
\hline
\end{tabular}

\section{Sentinel-1: Opportunities}

The simulator presented in the previous section allows for a quantitative estimation of the performances of Sentinel-1 mission in water resource management applications. In the following, some applications will be discussed and the quality of the expected products compared with those obtained in the framework of the WARM-SAR project (see Section 2). 


\subsection{DEM Estimation and Related Products}

The use of interferometric techniques for the evaluation of a DEM is in principle replicable with Sentinel-1 data. The difference in spatial resolution in stripmap mode ( $3 \mathrm{~m}$ for COSMO-SkyMed, $5 \mathrm{~m}$ for Sentinel-1) will cause a corresponding reduction of the resolution of the DEM from $9 \mathrm{~m}$ to $15 \mathrm{~m}$. Such a limitation is not significant for many of the applications proposed in the WARM-SAR project.

As discussed in Section 2, both optical and SAR data can provide observations of the reservoirs' retention area, while, in the absence of bathymetric information, the retained volumes remain unknown. To overcome this limitation, it is possible to use relationships between reservoirs' storage volumes and areas, which in case of homogeneous morphology can be valid for an entire region. For instance, an area-volume relation was developed in literature [34] performing an extensive bathymetric survey in the Upper East Region of Ghana:

$$
\text { Volume }=0.00857 \text { area }^{1.4367}
$$

Starting from SAR-derived data, a regression analysis was applied in order to obtain an area-volume relationship for the Yatenga district [15]:

$$
\text { Volume }=0.1012 \text { area }^{1.167}
$$

In order to assess the potentiality of Sentinel-1 data for this kind of application, the DEM acquired in the WARM-SAR project was resampled at the Sentinel-1 scale and a new dataset of area-volume for the Laaba reservoir was built. This dataset was compared to the one obtained for the same reservoir using the DEM extracted from COSMO-SkyMed satellite imagery in the WARM-SAR project framework.

The analysis of the DEMs was performed computing the areas of water surfaces at fixed heights, with a step of $0.3 \mathrm{~m}$. The water volumes stored in the reservoir for each step were calculated as a sum of those contained in each pixel of the water surface, which is assimilated to a water column, whose height $h_{w c}$ is given by:

$$
h_{w c}=h_{c}-h
$$

where $h_{c}$ is the elevation of the equipotential surface traced by the basin, and $h$ is the DEM height corresponding to the considered pixel. The water volume $V$ contained in the whole reservoir is then estimated as the summation of all the volume contributions, given as the product of the pixel area $S_{i}$ and the water column height $h_{w c}$ :

$$
V=\sum_{i} S_{i} \times h_{w c}
$$

In Figure 3, the results obtained through the DEM analysis and the application of the area-volume relationship proposed in [15] for the Yatenga region are plotted. The overall trend is similar for both the analyzed DEMs. An apparent anomaly occurs for low water surface areas in the Sentinel-like DEM (for example, three blue dots refer to the same area but to different volumes). This is because the lowest area values correspond to few pixels, which in the Sentinel-1 DEM have a surface of $225 \mathrm{~m}^{2}$. The higher resolution of COSMO-SkyMed-derived DEM made possible to compute more reliable values of the retained volume for such areas. This effect depends both on the morphology of the region and on the interpolation that produced differences in height between adjacent pixels greater than $0.3 \mathrm{~m}$. 
The above described effect allows the estimation of the range of areas that can be safely retrieved by Sentinel imagery. In principle, reservoirs covered by some thousands of square meters can be effectively monitored. We can also remark that the area-volume relationship proposed in [15] underestimates the reservoir volume when the water surface is in the range between 1000 and $20,000 \mathrm{~km}^{2}$.

Figure 3. Laaba's storage volumes as a function of the corresponding surface areas.

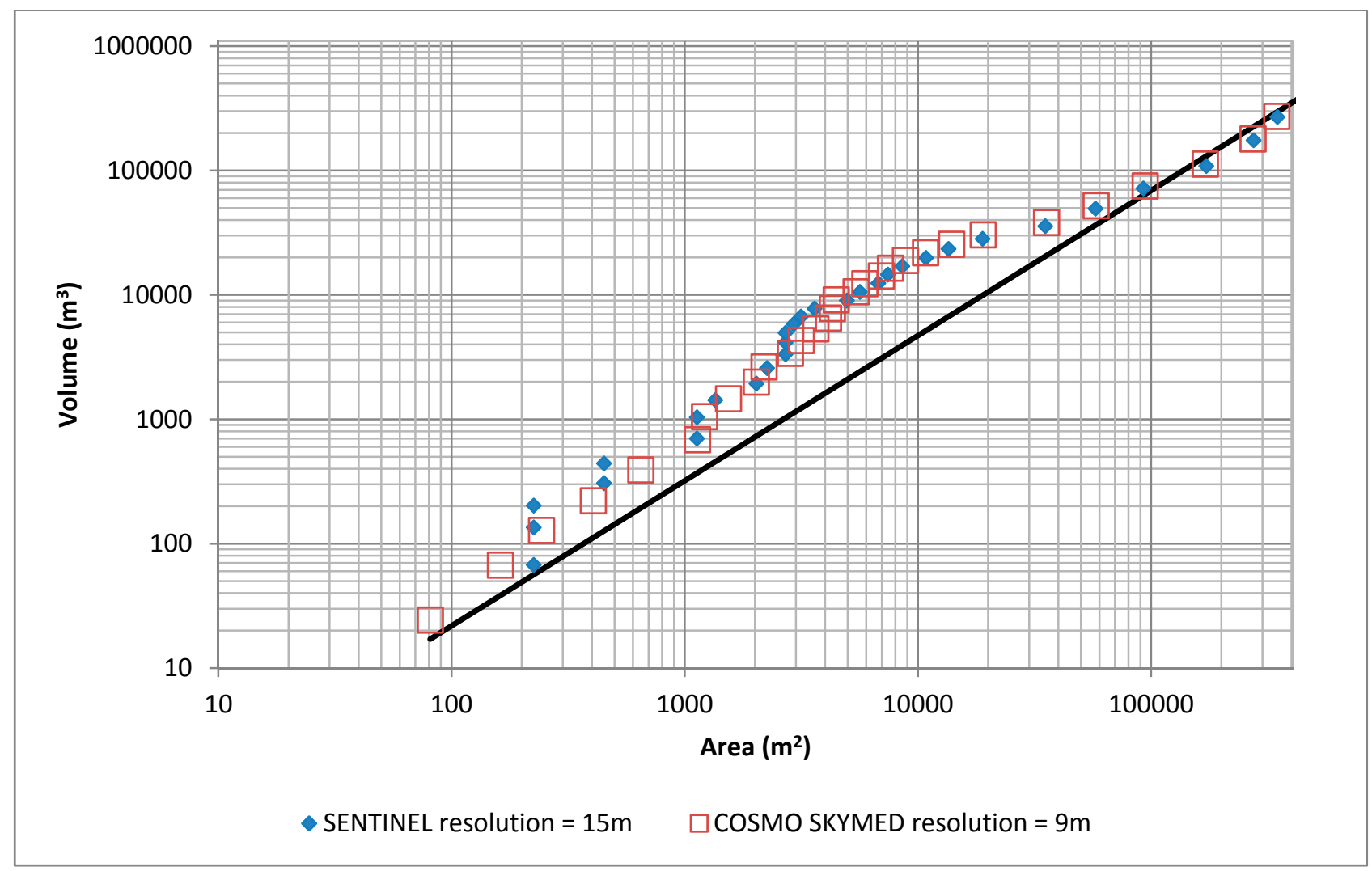

\subsection{Land Cover Map Production}

In this paragraph, we use the simulator presented in Section 4 to quantitatively evaluate how the land cover products developed in the frame of WARM-SAR can be replicated with Sentinel-1 data.

Table 3. Parameters used in the simulations

\begin{tabular}{ccc}
\hline Simulation Parameter & Terrain & Water \\
\hline$\varepsilon$ & 4 & 40 \\
$\sigma[\mathrm{S} / \mathrm{m}]$ & 0.001 & 1 \\
$H$ & 0.8 & 0.75 \\
$s\left[\mathrm{~m}^{1-H}\right]$ & 0.1 & 0.01 \\
\hline
\end{tabular}

As an example, we simulate the temporal evolution of the Laaba basin's water levels, by using an approach similar to that implemented in [34] for the simulation of flooded scenes. In particular, we modify the initial DEM (acquired when the basin is empty, see Section 2.2) reproducing the progressive filling of the basin with water-height steps of $0.5 \mathrm{~m}$. We set the roughness (Hurst coefficient $H$ and standard deviation at unitary distance $s$ ) and electromagnetic parameters (dielectric permittivity $\varepsilon$ and conductivity $\sigma$ ) of the 
terrain and water-filled area to typical values (see Table 3). In Figure 4, we show the DEMs with different water levels that were given as input to the simulator. It is worthwhile to note that with respect to the DEM presented in [23], a local adaptive filter (see [35]) has been applied in order to reduce the noise due to the presence of vegetation on the boundary of the water surface.

Figure 4. Laaba basin, 3D representation of the DEM used for SAR simulation. Water contour height: $341 \mathrm{~m} \mathrm{(a),} 340.5 \mathrm{~m}$ (b), $340 \mathrm{~m} \mathrm{(c),} 339.5 \mathrm{~m}$ (d), $339 \mathrm{~m}$ (e) and $338.5 \mathrm{~m}$ (f). A vertical stretching factor has been applied for visualization purposes.
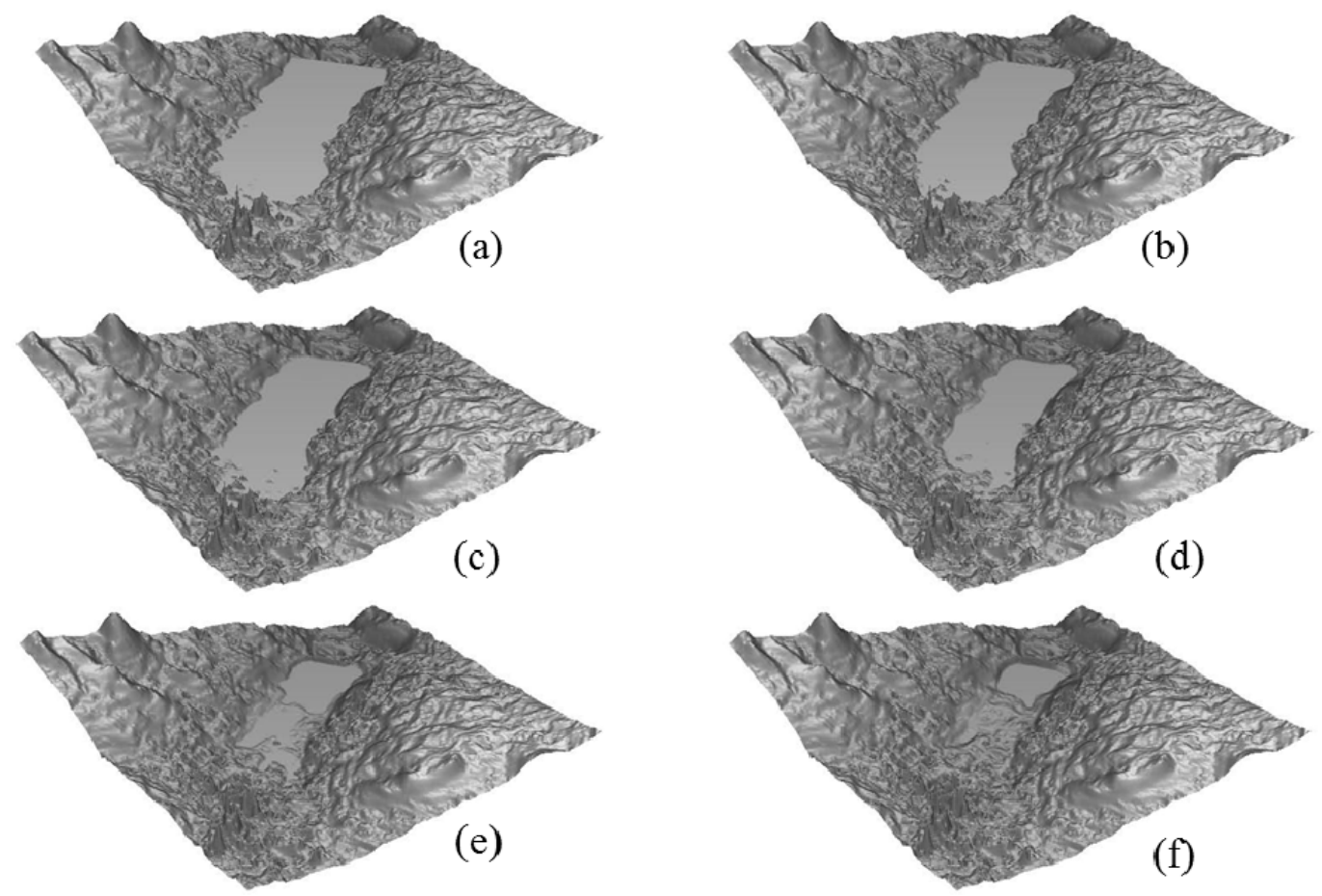

The simulated data have been processed in accordance with the approach presented in [19], where Level-1 $\alpha$ products were defined. In Figure 5, we show the simulated Level-1 $\alpha$ products for a scenario relevant to the Laaba reservoir, filled with different water levels. A simple classification rule, as explained in Section 2.4, allows the extraction of the water surface from the different acquisitions. It is worthwhile noting that, except for the area covered by water, the Level-1 $\alpha$ products exhibit a substantial balance between the test and reference intensity channels, providing an almost homogeneous cyan background. This is due to the fact that the simulator does not take into account the presence of vegetation, and the dielectric constant of terrains outside the reservoir was fixed to a constant value in all the simulated images.

The contrast between water and terrain backscattering is very similar to that of the actual COSMO-SkyMed data. This result is supported by the analysis of the expected backscattering at the $\mathrm{X}$ - and C-bands.

In Figure 6, we provide the backscattering coefficient of a typical rough soil, characterized by Hurst coefficient $H=0.8$ and standard deviation at unitary distance $s=0.1 \mathrm{~m}^{1-H}$, as a function of the incidence angles typical of remote-sensing applications (from 15 to 45 degrees). The curves have been evaluated with the small perturbation method (SPM) [31] for the HH polarization. The backscattering behavior is similar at the X-and C-bands. Similar results can be obtained at VV polarization. 
Figure 5. Laaba basin, simulated Sentinel-1 Level $1 \alpha$ products. Water contour height: (a) $341 \mathrm{~m}$, (b) $340.5 \mathrm{~m}$, (c) $340 \mathrm{~m}$, (d) $339.5 \mathrm{~m}$, (e) $339 \mathrm{~m}$ and (f) $338.5 \mathrm{~m}$. The spatial resolution is $5 \times 5 \mathrm{~m}$.

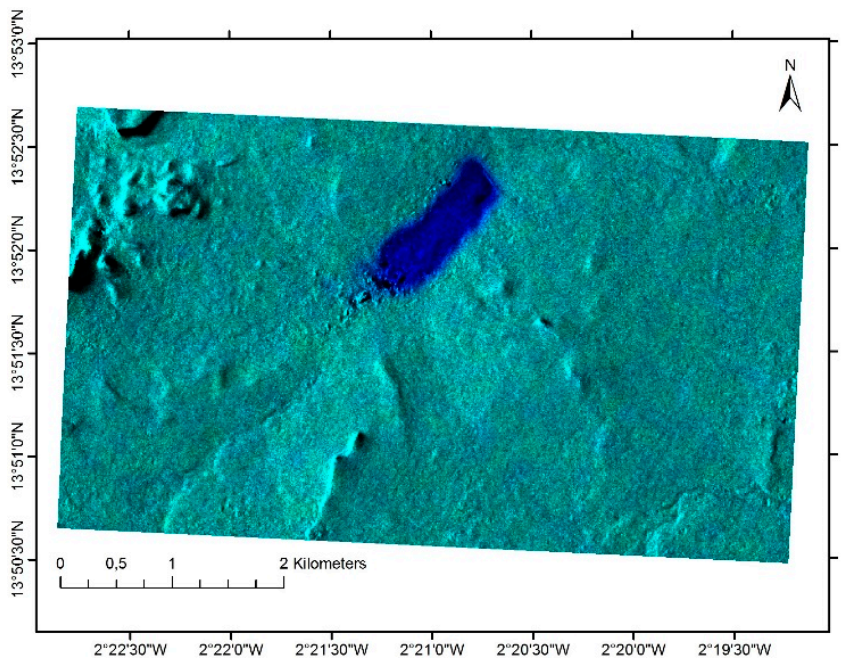

(a)

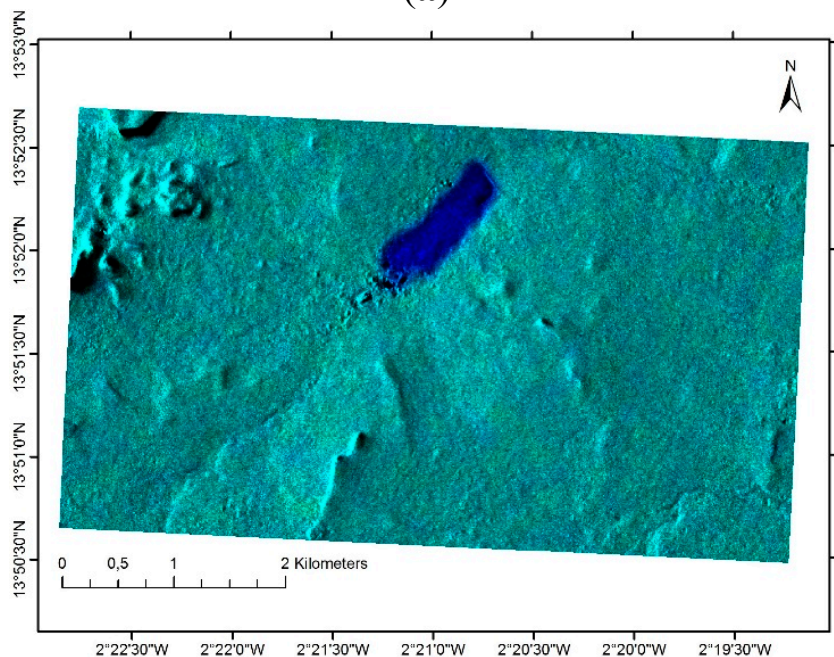

(c)

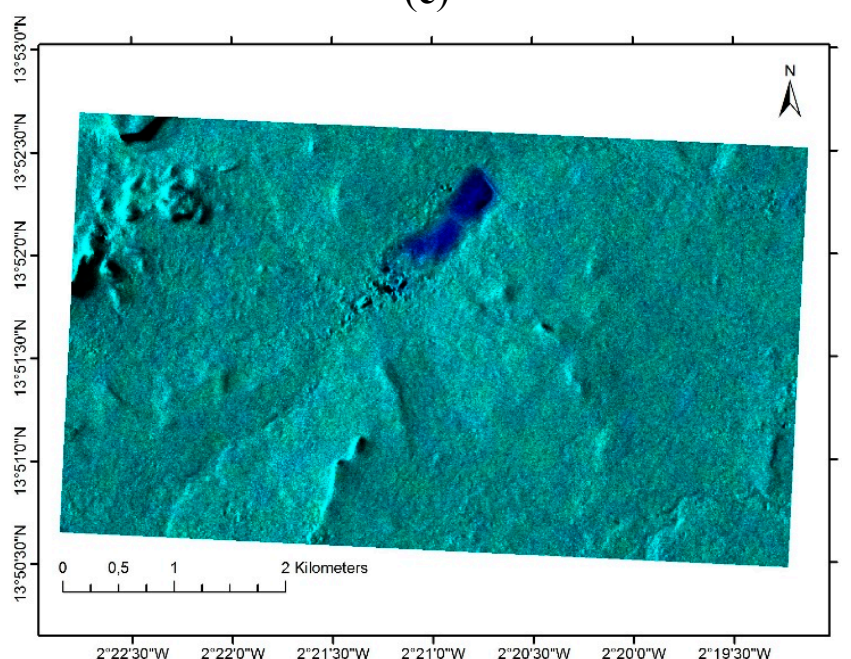

(e)

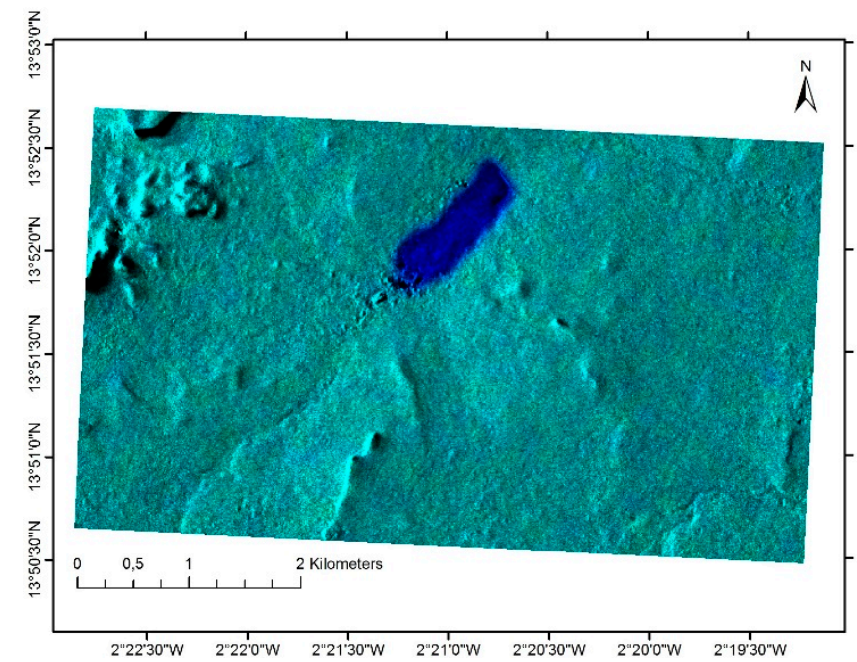

(b)

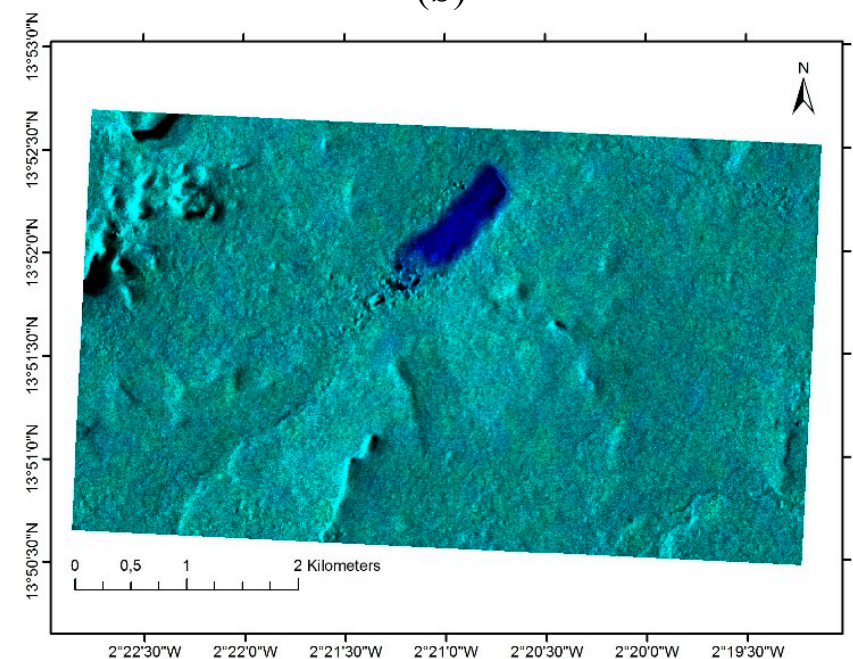

(d)

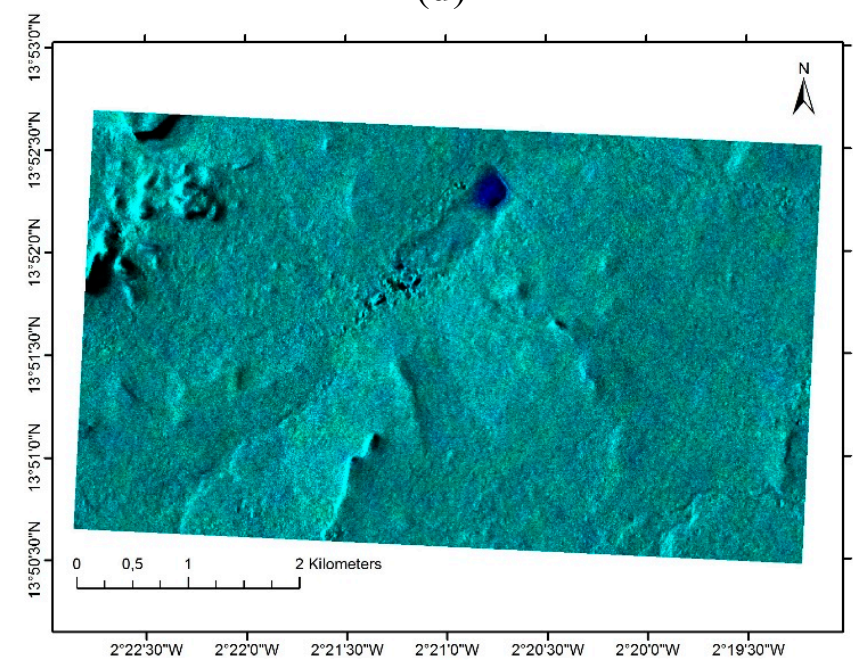

(f) 
Figure 6. Backscattering coefficient from a rough terrain as a function of the incidence angle, evaluated with the SPM at X- (blue line) and C- (red line) bands.

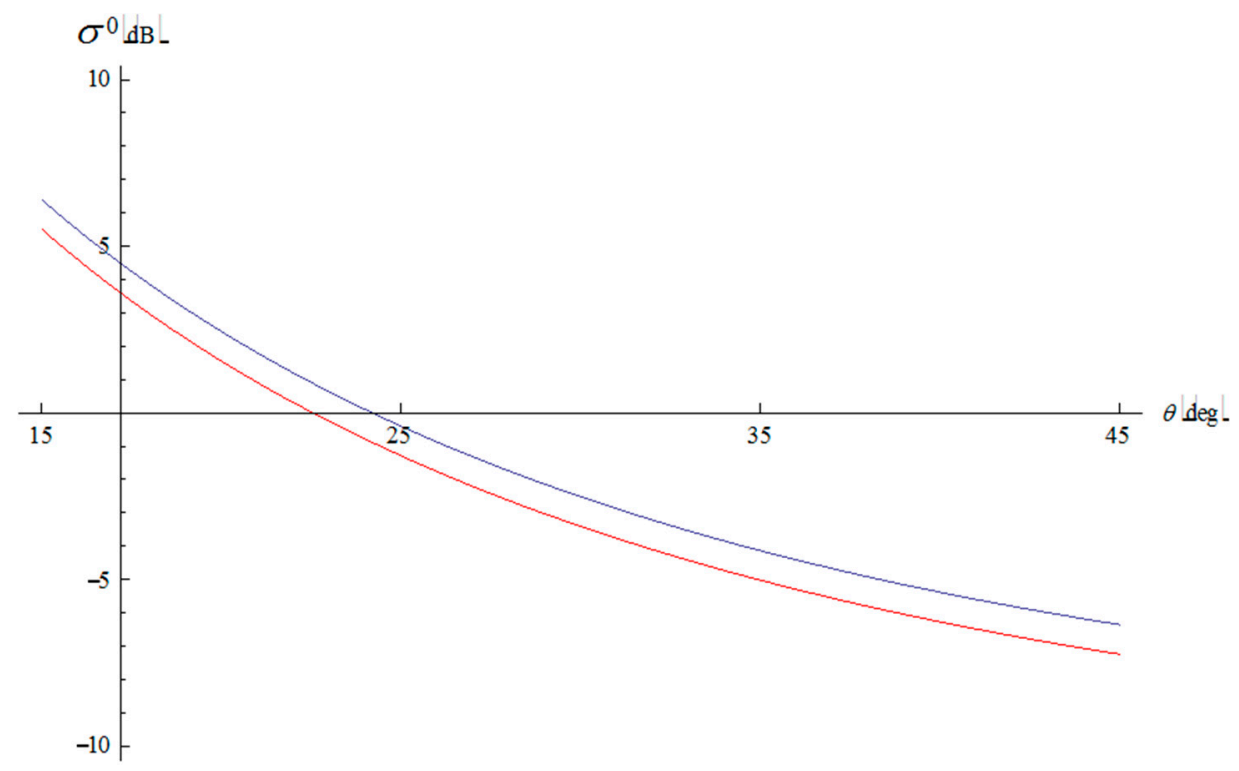

For water surface identification purposes, it is reasonable to analyze how the contrast between the water and the terrain backscattering is influenced by the frequency. In Figure 7, we plot the ratio between the backscattering coefficient of a rough terrain and of a water surface (see the parameters defined in Table 3) as a function of the incidence angle. The result shown in Figure 7 shows that, despite a small reduction, the contrast is still sufficient (almost $17 \mathrm{~dB}$ in the considered range of angles) to identify the area covered by water with the techniques presented in the frame of the WARM-SAR project.

Figure 7. Ratio between the backscattering coefficient of a rough terrain and of surface water as a function of the incidence angle evaluated with the SPM at X- (blue line) and C- (red line) bands.

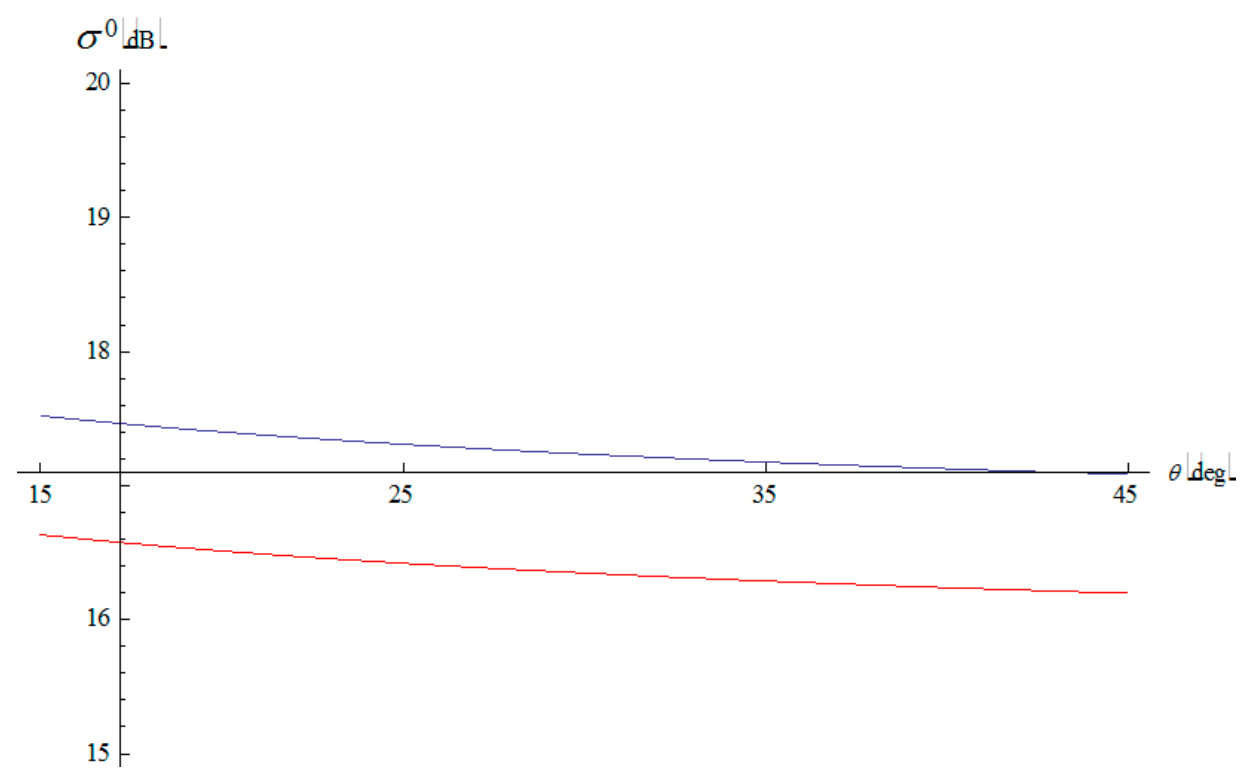




\subsection{Monitoring of Water Volumes Retained at Reservoirs}

In order to evaluate the potentiality of Sentinel-1 in measuring water volumes in semi-arid regions, we compared a series of simulated COSMO-SkyMed images superimposed to a $9 \mathrm{~m}$ spatial resolution DEM and a series of simulated Sentinel-1 images superimposed to a $15 \mathrm{~m}$ spatial resolution DEM for different levels of the water contour height. The results of the comparison are shown in Figure 8 for the Laaba reservoir. Such a comparison provides an estimation of the effect of the loss in spatial resolution introduced by Sentinel1 with respect to the COSMO-SkyMed products used in the WARM-SAR project.

Figure 8. Laaba basin: Surface water as function of the contour height.

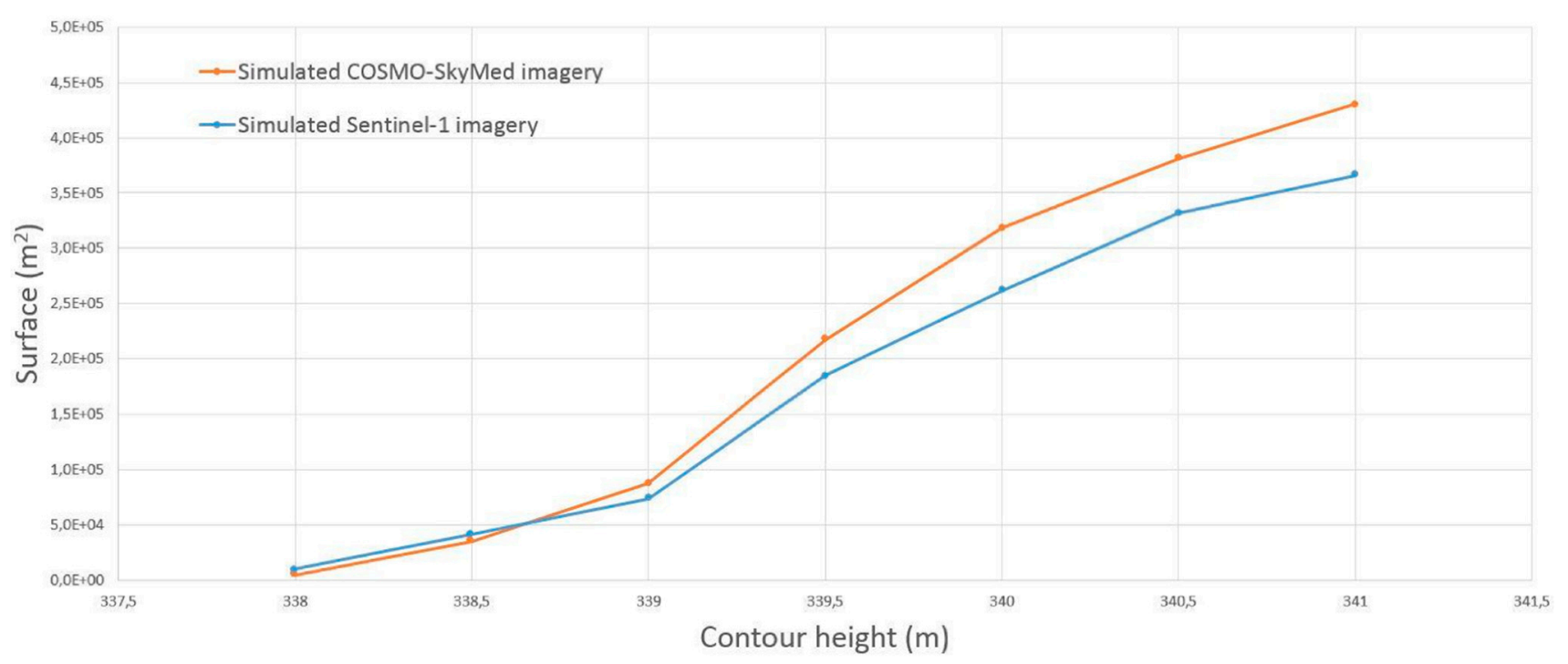

Figure 9. Laaba basin: retained water volume as function of the contour height.

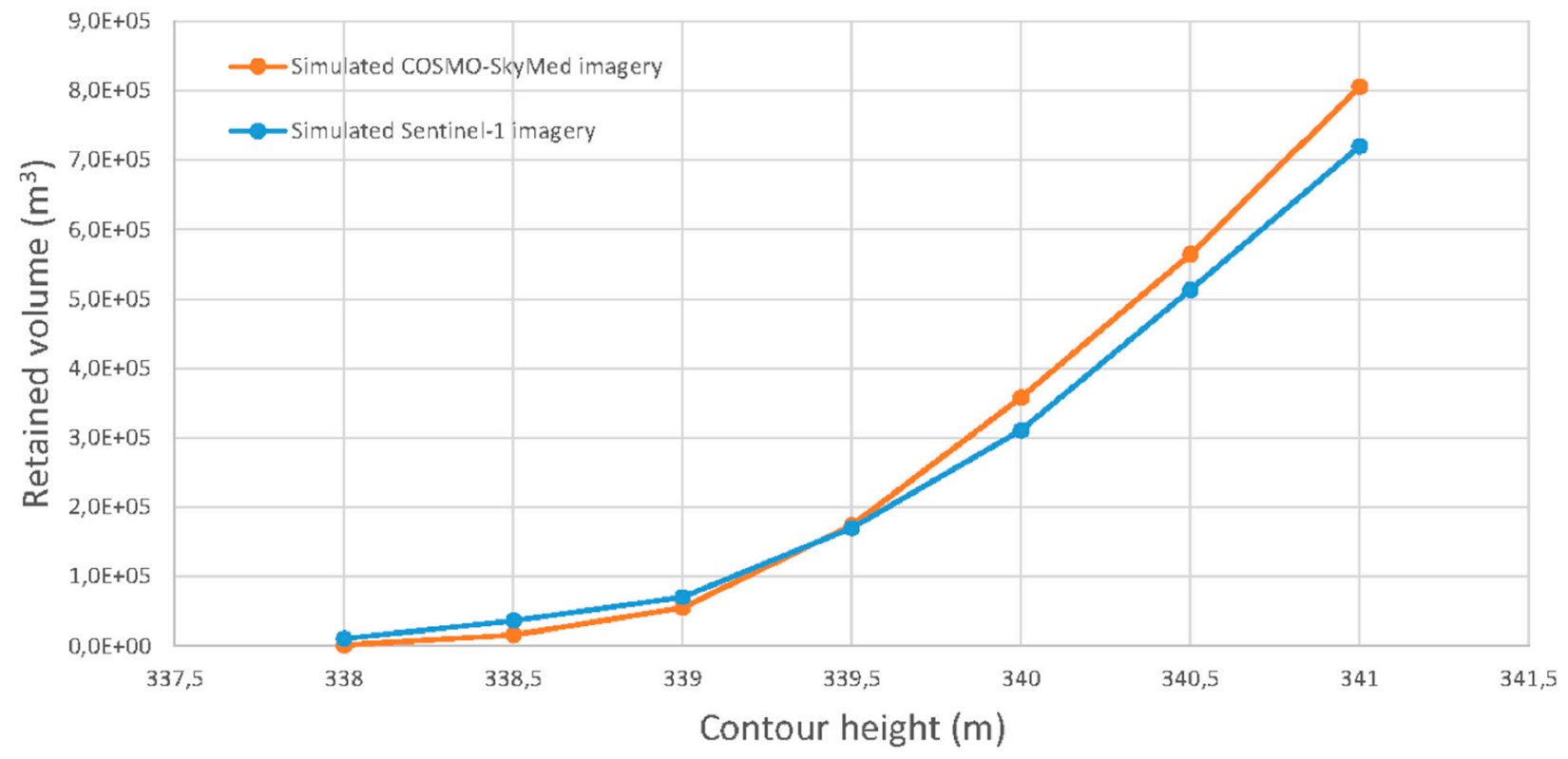

As expected, the discrepancy between Sentinel-1 (blue curve) and COSMO-SkyMed (orange curve) arises especially when the basin tends to fill up. In fact, when the water level increases, its contour is better 
delineated by the higher COSMO-SkyMed resolution. The error introduced by the loss in spatial resolution is in the order of $15 \%-20 \%$ and it is almost constant for water contour height $\in[339.5,341]$.

The estimated surface is then used for computing the water volume retained into the basin considering each pixel belonging to the water mask extracted from the simulated Level-1 $\alpha$ products as a water column, as explained in Section 5.1.

Results of this analysis are shown in Figure 9. The errors in the estimation of the surface areas do not affect significantly the retained volume calculation since they are mainly located at the boundary of the basin, where the contributions to the summation of (4) are small.

\section{Conclusions}

In this paper we explored the potentiality of the Sentinel-1 mission in providing data and value-added information for water resource management applications. The study has been supported by the use of a SAR raw signal simulator, achieving an innovative framework for the analysis of Sentinel-1 performances.

The results expected by the use of 5-meter resolution Sentinel-1 images in water-related projects were compared to those obtained by the use of 3-meter resolution COSMO-SkyMed imagery in the previously developed WARM-SAR project. The SAR raw signal simulator allowed the estimation of the expected differences of performances due to resolution and frequency. The quantification of the differences in the scattering mechanisms between the $\mathrm{X}$ - and $\mathrm{C}$-bands was also presented.

Three classes of applications were investigated: (i) the creation of an interferometric DEM and related products, (ii) the production of land cover maps, and (iii) the monitoring of water volumes retained at reservoirs.

As for the interferometric applications, the ratio between Cosmo-SkyMed and Sentinel-1 resolution is 0.6. Such a factor quantifies also the loss of resolution on the production of the DEM. In addition, we achieved a quantitative estimation of the degradation of performances that would be obtained by replicating most of the products obtained in WARM-SAR with Sentinel-1 data. In particular, we experimented that the Sentinel-1 and COSMO SkyMed derived DEM provide comparable results in the extraction of the relation between reservoir surface area and retained water volume for all the reservoirs whose extension is higher than one thousand square meters.

As for the production of land cover maps, the SAR raw signal simulator led us to simulate, present and interpret Sentinel-1 Level-1 $\alpha$ products. Appropriate electromagnetic models were used to demonstrate that the radiometric contrast between water and rough surfaces at the $\mathrm{C}$ band is about $2 \mathrm{~dB}$ lower than at $\mathrm{X}$ band for incidence angles in the range between $15^{\circ}$ and $45^{\circ}$. Such a result demonstrates that land cover maps obtained by Sentinel-1 will guarantee class separation comparable to that obtained by Cosmo-SkyMed images.

As for the monitoring of water volumes retained by reservoirs, we experimented that the loss in spatial resolution introduced by Sentinel-1 imagery produces a discrepancy in the order of $15 \%-20 \%$ in the estimation of reservoir surface area with respect to COSMO-SkyMed images. However, this error is reduced to about $12 \%$ in the estimation of retained volumes since it is limited at the reservoirs' borders.

In synthesis, this work presented a new framework for simulating Sentinel-1 data and related products. It provides the opportunity to predict and control quality parameters of the Sentinel-1 SAR data and 
products, whose high informative content, conjugated with the open access policy, represents an extraordinary opportunity for future projects, mainly in low-income countries.

\section{Acknowledgments}

The SAR images, at the basis of the study, were provided by the Italian Space Agency (ASI) under the aegis of the 2007 COSMO-SkyMed AO Project "Use of High Resolution SAR Data for Water Resource Management in Semi Arid Regions" and of the HydroCIDOT project.

\section{Author Contributions}

All authors contributed extensively to the work presented in this paper. Donato Amitrano, Gerardo Di Martino, Antonio Iodice, Daniele Riccio and Giuseppe Ruello were in charge of modeling, simulating and processing SAR data. Maria Nicolina Papa and Francesco Mitidieri were in charge of implementing the hydrological models.

\section{Conflicts of Interest}

The authors declare no conflict of interest.

\section{References}

1. UNWater Water Scarcity. Available online: http://www.unwater.org/fileadmin/user_upload/water cooperation2013/doc/Factsheets/water_scarcity.pdf (accessed on 28 October 2013).

2. United Nations Department of Economic and Social Affairs (UNDESA). Population Division World Population Prospects; The 2008 Revision, Highlights; UNDESA: New York, NY, USA, 2009.

3. UNESCO. The United Nations World Water Development Report 4: Managing Water under Uncertainty and Risk; UNESCO: Paris, France, 2012.

4. International Crops Research Institute for the Semi-Arid Tropics (ICRISAT). Climate Change and Desertification Put One Billion Poor People at Risk; ICRISAT: Hyderabad, India, 2008.

5. New Partnership for Africa's Development (NEPAD). Water in Africa: Management Options to Enhance Survival and Growth; United Nations Economic Commission for Africa (UNECA): Addis Ababa, Ethiopia, 2006.

6. Eilander, D.; Annor, F.O.; Iannini, L.; van de Giesen, N. Remotely sensed monitoring of small reservoir dynamics : A bayesian approach. Remote Sens. 2014, 6, 1191-1210.

7. Towards an Atlas of Lakes and Reservoirs in Burkina Faso. Available online: http://www.smallreservoirs.org/full/toolkit/docs/IIa\%2002\%20Faso\%20MAB_ML.pdf (accessed on 4 November 2014).

8. Annor, F.O.; van de Giesen, N.; Liebe, J. Monitoring of small reservoirs storage using envisat ASAR and spot imagery in the upper east region of Ghana. In Application of Satellite Remote Sensing to Support Water Resources Management in Africa: Results from the TIGER Initiative; IHP-VII Technical Documents in Hydrology; UNESCO: Paris, France, 2010. 
9. Liebe, J.R.; van de Giesen, N.; Andreini, M.S.; Steenhuis, T.S.; Walter, M.T. Suitability and limitations of ENVISAT ASAR for monitoring small reservoirs in a Semiarid Area. IEEE Trans. Geosci. Remote Sens. 2009, 47, 1536-1547.

10. Alsdorf, D.E.; Rodriguez, E.; Lettenmaier, D.P. Measuring surface water from space. Rev. Geophys. 2007, 45, 1-24.

11. The TIGER Initiative 2009-2012 Report. Looking for Warter in Africa. Available online: http://www.tiger.esa.int/files/pdf/tiger_report_single_pages_lowres.pdf(accessed on 28 October 2014).

12. Saradeth, S.; Dodo, A.K.; Latrech, D. Earth observation in support of management of internationally shared groundwater resources in Africa: The AQUIFER project. In Application of Satellite Remote Sensing to Support Water Resources Management in Africa: Results from the TIGER Initiative; IHP-VII Technical Documents in Hydrology; UNESCO: Paris, France, 2010.

13. Thomas, A.; Ayuk, J. Land use/land cover mapping of the Kuils-Eerste River catchment (Western Cape) through an integrated approach using remote sensing and GIS. In Application of Satellite Remote Sensing to Support Water Resources Management in Africa: Results from the TIGER Initiative; IHP-VII Technical Documents in Hydrology; UNESCO: Paris, France, 2010.

14. Arledler, A.; Castracane, P.; Marin, A.; Mica, S.; Pace, G.; Quartulli, M.; Vaglio Laurin, G.; Alfari, I.; Trebossen, H. Detecting water bodies and water related features in the Niger basin area by SAR data: The ESA TIGER WADE project. In Application of Satellite Remote Sensing to Support Water Resources Management in Africa: Results from the TIGER Initiative; IHP-VII Technical Documents in Hydrology; UNESCO: Paris, France, 2010.

15. Amitrano, D.; Ciervo, F.; Di Martino, G.; Papa, M.N.; Iodice, A.; Koussoube, Y.; Mitidieri, F.; Riccio, D.; Ruello, G. Modeling watershed response in semi-arid regions with high resolution synthetic aperture radars. IEEE J. Sel. Top. Appl. Earth Obs. 2014, 7, 2732-2745.

16. Liebe, J.R.; van de Giesen, N.; Andreini, M.; Walter, M.T.; Steenhuis, T.S. Determining watershed response in data poor environments with remotely sensed small reservoirs as runoff gauges. Water Resour. Res. 2009, 45, doi:10.1029/2008WR007369.

17. Toutin, T. Geometric processing of remote sensing images: Models, algorithms and methods. Int. J. Remote Sens. 2004, 25, 1893-1924.

18. Gaetano, R.; Amitrano, D.; Masi, G.; Poggi, G.; Verdoliva, A.; Ruello, G.; Scarpa, G. Exploration of Multitemporal COSMO-SkyMed data via tree-structured MRF segmentation. IEEE J. Sel. Top. Appl. Earth Obs. 2014, 7, 2763-2775.

19. Amitrano, D.; Di Martino, G.; Iodice, A.; Riccio, D.; Ruello, G. A New framework for SAR multitemporal data RGB representation: Rationale and products. IEEE Trans. Geosci. Remote Sens. 2015, 53, 117-133.

20. Datcu, M.; Seidel, K. Human centered concepts for exploration and understanding of earth observation images. IEEE Trans. Geosci. Remote Sens. 2005, 43, 52-59.

21. Di Martino, G.; Iodice, A.; Natale, A.; Riccio, D.; Ruello, G.; Zinno, I.; Koussouben, Y.; Papa, M.N.; Ciervo, F. COSMO-SkyMed AO Projects-Use of high resolution SAR data for water resource management in Semi Arid Regions. In Proceedings of the IEEE International Geoscience and Remote Sensing Symposium, Munich, Germany, 22-27 July 2012; pp. 1212-1215. 
22. The Food and Nutrition Crisis in the Sahel. Urgent Action to Support the Resilience of Vulnerable Populations. Available online: http://www.fao.org/fileadmin/user_upload/emergencies/docs/DocProg \%20FAO\%20SAHEL\%20EN\%20short\%20version.pdf (accessed on 28 October 2014).

23. Amitrano, D.; Di Martino, G.; Iodice, A.; Ruello, G.; Ciervo, F.; Papa, M.N.; Koussoube, Y. Effectiveness of high-resolution SAR for water resource management in low-income semi-arid countries. Int. J. Remote Sens. 2014, 35, 70-88.

24. Grimaldi, S.; Angeluccetti, I.V.; Coviello, V.; Vezza, P. Cost-effectiveness of soil and water conservation measures on the catchement sediment budget-The Laaba watershed case study, Burkina Faso. Land Degrad. Dev. 2013, 2013, doi:10.1002/1dr.2212.

25. Warren, A.; Batterbury, S.; Osbahr, H. Soil erosion in the West African Sahel: A review and an application of a "local political ecology" approach in South West Niger. Glob. Environ. Chang. 2001, 11, 79-95.

26. Healey, C.; Booth, K.S.; Enns, J. Visualizing real-time multivariate data using preattentive processing. ACM Trans. Model. Comput. Simul. 1995, 5, 190-221.

27. Fung, A.K. Scattering from a vegetation layer. IEEE Trans. Geosci. Elect. 1979, 17, 1-6.

28. De Grandi, G.F.; Leysen, M.; Lee, J.-S.; Schuler, D. Radar reflectivity estimation using multiple SAR scenes of the same target: Technique and applications. In Proceedings of the IEEE International Geoscience and Remote Sensing Symposium, Singapore, 3-8 August 1997; pp. 1047-1050.

29. Malenovský, Z.; Rott, H.; Cihlar, J.; Schaepman, M.E.; García-Santos, G.; Fernandes, R.; Berger, M. Sentinels for science: Potential of Sentinel-1, -2, and -3 missions for scientific observations of ocean, cryosphere, and land. Remote Sens. Environ. 2012, 120, 91-101.

30. Franceschetti, G.; Migliaccio, M.; Riccio, D.; Schirinzi, G. SARAS: A synthetic aperture radar (SAR) raw signal simulator. IEEE Trans. Geosci. Remote Sens. 1992, 30, 110-123.

31. Franceschetti, G.; Riccio, D. Scattering, Natural Surfaces and Fractals; Academic Press: Burlington, MA, USA, 2007.

32. Goodman, J.W. Some fundamental properties of speckle. J. Opt. Soc. Am. 1976, 66, doi:10.1364/JOSA.66.001145.

33. Di Martino, G.; Iodice, A.; Riccio, D.; Ruello, G. A physical approach for SAR speckle simulation: First results. Eur. J. Remote Sens. 2013, 46, 823-836.

34. Liebe, J.R.; van de Giesen, N.; Andreini, M.S. Estimation of small reservoir storage capacities in semi-arid environment: A case study in the Upper East Region of Ghana. Phys. Chem. Earth. 2005, 30, 448-454.

(C) 2014 by the authors; licensee MDPI, Basel, Switzerland. This article is an open access article distributed under the terms and conditions of the Creative Commons Attribution license (http://creativecommons.org/licenses/by/4.0/). 